\title{
Vasoplegic Syndrome After Cardiovascular Surgery: A Review of Pathophysiology and Outcome Oriented Therapeutic Management
}

\author{
Vishnu Datt ${ }^{1}$, Rachna Wadhwa ${ }^{1}$, Varun Sharma ${ }^{1}$, Sanjula Virmani ${ }^{2}$, Harpreet Minhas ${ }^{1}$, \\ and Shardha Malik ${ }^{1}$ \\ ${ }^{1}$ GB Pant Hospital \\ ${ }^{2} \mathrm{G}$ B Pant Hospital
}

June 5, 2021

\begin{abstract}
Vasoplegic syndrome (VPS) is defined as systemic hypotension due to profound vasodilatation and loss of systemic vascular resistance (SVR), despite normal or increased cardiac index (CI). It occurs in 9- 44\% of cardiac surgery patients after cardiopulmonary bypass (CPB) and is associated with significant morbidity and mortality. The pathogenesis of VPS is multifactorial involving the activation of contact, coagulation, and complement systems and the activation of leukocytes. platelets and endothelial cells resulting in an imbalance in the regulation of the vascular tone; inducible nitric oxide synthase [iNOS] triggered by inflammatory cytokines during CPB produces nitric oxide (NO), which increases vascular levels of cyclic guanosine monophosphate (cGMP), resulting in vasodilation. leading to postcardiac surgery VPS. Standard treatment options for severe refractory VPS are extremely limited and include vasopressor support. latest Surviving Sepsis Campaign guidelines also consider that the best therapeutic management of vascular hypo- responsiveness to vasopressors could be a combination of multiple vasopressors, including norepinephrine (NE) and early prescription of vasopressin. This review will address the various definitions, risk factors, pathophysiology, potential cardiac candidates, and potential therapeutic interventions for VPS following cardiac surgery focussed on the outcome. This review did not require any ethical approval or consent from the patients.
\end{abstract}

Title Page

Title: Vasoplegic Syndrome After Cardiovascular Surgery: A Review of Pathophysiology and Outcome Oriented Therapeutic Management

Authors: Vishnu Datt, DA, DNB, MNAMS,1,2,3, Rachna Wadhhwa, MD1,2, Varun Sharma, MD1,2, Sanjula Virmani, DA, DNB2, HS Minhas, McH3, Shardha Malik DA, DNB,1,2

Affiliation : Department of Cardiac Anaesthesia and Cardiothoracic and vascular Surgery, GB Pant Hospital [GIPMER], New Delhi, India

Running Title: Vasoplegic syndrome

Sources of Funding: None

conflict of interest: None

\section{Author for Correspondence:}

Dr Vishnu Datt, Director Professor, Cardiac Anaesthesia,

Address:

Room No. 629, Academic Block, 
G B Pant hospital [GIPMER],

JLN Marg, New Delhi-110002

Phone no.99-011- 9718599406

E-mail; dattvishnu@yahoo.com

\section{Covering letter}

To,

The Editor in chief,

JOCS

Sub: Submission of manuscript for publication.

Respected sir,

We are hereby submitting a manuscript entitled "Vasoplegic Syndrome After Cardiovascular Surgery: A Review of Pathophysiology and Outcome Oriented Therapeutic Management

" for publication in your journal for a Review. We wish to state that the manuscript has not been published earlier and is not under consideration for publication anywhere else. The informed consent was taken from the parents and that is mentioned in the manuscript.

The source of funding and conflict of interest: $\mathrm{N}$ il.

Authors with institutional affiliation:

1. Vishnu Datt, DA, DNB, Director professor, Department of cardiac Anaesthesia, GB Pant hospital[GIPMER], New Delhi,India[Corresponding author]

2.Rachna Wadhwa MD, Associate Professor, Department of cardiac Anaesthesia, GB Pant Hospital [GIPMER], new Delhi, India

3.Varun Sharma, MD, DNB Fellow, Department of cardiac Anaesthesia, GB Pant Hospital [GIPMER], New India

4. Sanjula Virmani, DA DNB, Director professor, department of cardiac Anaesthesia, GB Pant Hospital [GIPMER], New Delhi, India

5. HS Minhas McH, Professor, Department of cardio thoracic and vascular surgery, GB Pant Hospital, [GIPMER], New Delhi

6. Shardha DNB, Assistant Professor, Department of cardiac Anaesthesia, GB Pant Hospital [GIPMER], new Delhi, India

Institute ; Department of cardiac Anesthesia and Cardiothoracic and Vascular surgery, GIPMER, New Delhi. India

Thanks, and Regards.

Yours sincerely,

DR Vishnu Datt \& co-authors

Corresponding author's Address.

Dr Vishnu Datt, Director Professor, Cardiac Anaesthesia, Room No. 629, Academic Block, 
G B Pant hospital, New Delhi-2

\section{Phone no.99-011- 9718599406}

\section{E-mail; dattvishnu@yahoo.com}

\section{Hosted file}

VPS_Final1.docx available at https://authorea.com/users/413861/articles/524973-vasoplegicsyndrome-after-cardiovascular-surgery-a-review-of-pathophysiology-and-outcome-orientedtherapeutic-management

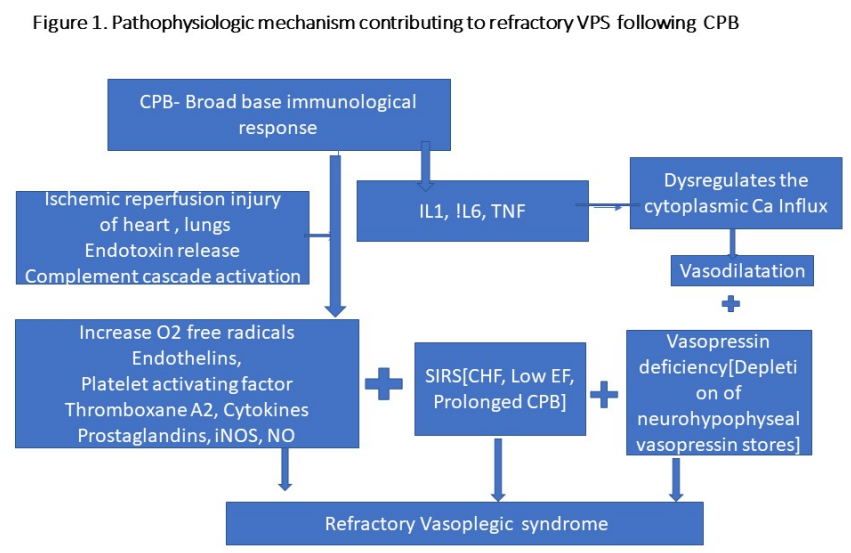

\section{Hosted file}

Fig 2- systematic practical approach.docx available at https://authorea.com/users/ 413861/articles/524973-vasoplegic-syndrome-after-cardiovascular-surgery-a-review-ofpathophysiology-and-outcome-oriented-therapeutic-management

\section{Hosted file}

table VPS.docx available at https://authorea.com/users/413861/articles/524973-vasoplegicsyndrome-after-cardiovascular-surgery-a-review-of-pathophysiology-and-outcome-orientedtherapeutic-management 